\title{
Mesoscale Data Assimilation Experiment in the WWRP B08RDP
}

\author{
Masaru Kunii, Kazuo Saito and Hiromu Seko \\ Meteorological Research Institute, Tsukuba, Japan
}

\begin{abstract}
A mesoscale data assimilation experiment was performed for the Beijing 2008 Olympics Research and Development Project (B08RDP) under the World Weather Research Program (WWRP) conducted during the period around the Beijing 2008 Olympic Games.

In this experiment, the Japan Meteorological Agency (JMA) hydrostatic mesoscale 4D-Var analysis system was modified and utilized to produce accurate initial fields over the China area. In addition to the conventional observations, precipitation data observed by rain-gauges were assimilated as well as data produced from a nowcasting system of the Australian Bureau of Meteorology.

The analysis system with rainfall data outperformed other experiments, i.e., the mesoscale analysis without precipitation data and the JMA global analysis, with its quantitative precipitation forecast. This shows that the assimilation of precipitation data can have a positive impact on subsequent model forecasts and that it would be effective even for areas where successive rainfall observations are sparse.
\end{abstract}

\section{Introduction}

The WWRP short-range weather forecasting research project was conducted for the Beijing 2008 Olympic Games. The project was divided into two components; One was the Forecast Demonstration Project (B08FDP) with a forecast time (FT) of 0 to 6 hours based on nowcasting, and the Research and Development Project (B08RDP) with FT $=6-36$ hours based on a mesoscale ensemble prediction (MEP). Collaborating with the Numerical Prediction Division of JMA, the Meteorological Research Institute (MRI) participated in the B08RDP component, employing the JMA nonhydrostatic model (NHM; Saito et al. 2006) with a horizontal resolution of $15 \mathrm{~km}$ for a MEP of 11 members in near real time. In addition to MRI/JMA, the National Centers for Environmental Prediction (NCEP; US), the Meteorological Service of Canada (MSC; Canada), Zentral Anstalt fur Meterologie und Geodynamik and Meteo-France (ZAMG; Austria and France), the National Meteorological Center of the China Meteorological Administration (NMC; China), and the Chinese Academy of Meteorological Sciences (CAMS; China) participated in the RDP component. MRI's activities related to B08FDP/RDP are given by Saito et al. (2010).

In the B08RDP experiment, initial conditions for the MEP system needed to be prepared by each participant. Needless to say, the accuracy of the analysis field is essential for MEP because it can be regarded as the center of the probability density function of the initial states.

Since JMA terminated regional analysis in November 2007, only the JMA global analysis (GA) was available for near-realtime experiments over the full domain of B08RDP as of Summer 2008. However, the horizontal resolution of the inner model of global 4D-Var in GA (T159; about $80 \mathrm{~km}$ ) was not fine enough for mesoscale numerical predictions. There are also distinct disparities between GA and the subsequent mesoscale model, such as the land-surface processes, which would make it difficult to execute

Corresponding author: Masaru Kunii, Meteorological Research Institute, 1-1 Nagamine, Tsukuba 305-0052, Japan. E-mail: mkunii@mri-jma.go.jp. (C) 2010, the Meteorological Society of Japan. the model forecast.

In order to assimilate the observational data with high resolution and to produce more accurate initial fields than GA, the JMA mesoscale 4D-Var analysis system (Meso 4D-Var), which was originally designed to cover the area around Japan, was modified so as to permit its use in the China area. In addition to conventional observational data, precipitation data observed by rain gauges in China were assimilated by the Meso 4D-Var. Moreover, we tested the impact of the precipitation analysis performed by the Australian Bureau of Meteorology in FDP (Seed 2009). These trials were carried out following the work of Koizumi et al. (2005), which examined the impact of the assimilation of a rainfall analysis produced by a nowcasting project.

The purpose of this work was to produce accurate initial fields in near real time for the MEP experiments conducted in the WWRP B08RDP by constructing a regional data assimilation system over China, and to assess the impact of the assimilation of precipitation data on the subsequent model forecast. The specifications of the analysis system and the assimilation of precipitation data are described in Sections 2 and 3. We present the verification results in Section 4. Finally, we summarize this study in Section 5.

\section{Meso 4D-Var application for B08RDP}

\subsection{Construction of the experimental system}

The Meso 4D-Var analysis system (Ishikawa and Koizumi 2002) was developed based on the JMA hydrostatic mesoscale spectral model. Since the original domain $(3600 \mathrm{~km} \times 2880 \mathrm{~km})$ covered only Japan and its surrounding areas, we shifted and expanded the domain to fully cover the common verification region of B08RDP with the margins at the lateral boundaries (Fig. 1). The domain size was $3600 \mathrm{~km} \times 3200 \mathrm{~km}$, and the number of vertical levels was 40 , from the surface up to $10 \mathrm{hPa}$. An incremental method was used for the iteration procedure in the 4D-Var system to enhance the computation efficiency. The inner model had a 20 $\mathrm{km}$ horizontal resolution, which was coarser than that of the outer model, at $10 \mathrm{~km}$.

In the JMA data-assimilation systems, the background error statistics are calculated using the NMC (National Meteorological Center, later National Centers for Environmental Prediction (NCEP)) method (Parrish and Derber 1992). Strictly speaking, if the model domain is changed, the background error statistics should be re-calculated. In this study, the same statistics as in the original 4D-Var were used for simplicity, based on the assumption that the statistics over East Asia are not significantly different.

The assimilation window length was 3 hours, with the observational data collected into four 1-hour time slots. Typical observational data are obtained from radiosondes, land stations, pilot balloons, wind profilers, aircrafts, ships, and buoys. In addition to these conventional data, the JMA's Radar-Raingauge analyzed precipitation (estimated by weather radars and calibrated by groundbased rain gauges) over Japan and satellite-retrieved data from the Special Sensor Microwave/Imager (SSM/I), The Tropical Rainfall Measuring Mission Microwave Imager (TMI) and the Advanced Microwave Scanning Radiometer for Earth Observing System (AMSR-E) were assimilated as a 1-hour precipitation amount or as total precipitable water (TPW). QuikSCAT sea-surface winds and radial velocity data for operational Doppler radars in Japan were also assimilated. These features are summarized in Table 1.

\subsection{Near real-time operation}

In the B08RDP experiment, all participants operated their 
Table 1. Specifications of the Meso 4D-Var.

\begin{tabular}{ll}
\hline \multicolumn{1}{c}{ Point } & \multicolumn{1}{c}{ Description } \\
\hline Domain size & $3600(\mathrm{~km}) \times 3200(\mathrm{~km})$ \\
Grid number & $181 \times 161 \times 40$ \\
Horizontal resolution & $20(\mathrm{~km})$ \\
Assimilation window & 3 hours \\
Initial condition & JMA global analysis (TL959L60) \\
Boundary condition & JMA global forecast (TL959L60) \\
Observational data & $\begin{array}{l}\text { radiosonde, land station, pilot balloon, wind } \\
\text { profiler, aircraft, ship, buoy, Radar-Raingauge } \\
\text { analyzed precipitation, precipitation amount and } \\
\\
\text { TPW retrieved from SSM/I, TMI and AMSR-E, } \\
\text { QuikSCAT sea surface winds, Doppler radar } \\
\text { radial wind. }\end{array}$ \\
\hline
\end{tabular}

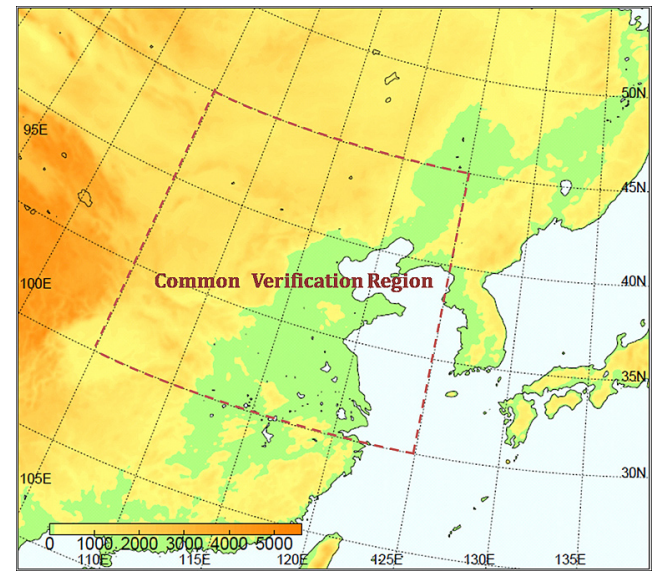

Fig. 1. Domain of the Meso 4D-Var applied to B08RDP. The area surrounded by dashed lines is the common verification region of the B08RDP experiment.

MEP systems once a day, initialized at 1200 UTC, for up to 36 hours. Considering the computational resources, we arranged for the data assimilation cycle to be conducted over just 6 hours, from 0600 UTC to 1200 UTC, without a continuous analysisforecast cycle. To reduce the discrepancy factors between the analysis model (20 km hydrostatic model) and the forecast model (15 km NHM), the incremental forecast in the second assimilation window (0900 to 1200 UTC) was performed using the $15 \mathrm{~km}$ NHM. Using the forecast of the $15 \mathrm{~km} \mathrm{NHM}$ for analysis fields, the cloud microphysical variables (cloud water, cloud ice, rain, and graupel) at 1200 UTC were given at the initial time of MEP. This method effectively avoids underestimation of the precipitation in the spin-up period (Ishida and Saito 2005). A similar method has been employed in the JMA operational mesoscale forecast (Aranami and Hara 2006).

In order to utilize as much observational data as possible in the assimilation cycle, the system was employed after waiting for the arrival of radiosonde data in China at 1200 UTC. These data have a time lag of a few hours and are not assimilated in the operational mesoscale analysis at JMA. Since the B08RDP participants were requested to send the MEP results to CMA by 2230 UTC, this waiting time could constrain the schedule for subsequent job steps, such as ensemble forecasting. However, preliminary experiments indicated that the forecast accuracy was clearly degraded if the upper soundings over China at 1200 UTC were not assimilated (Fig. 2).

Special treatment was required to prepare soil temperatures in Meso 4D-VAR at the beginning of the assimilation cycle because the Simple Biosphere scheme ( $\mathrm{SiB})$ is used in the JMA global model, whereas four-layer soil temperatures are predicted using
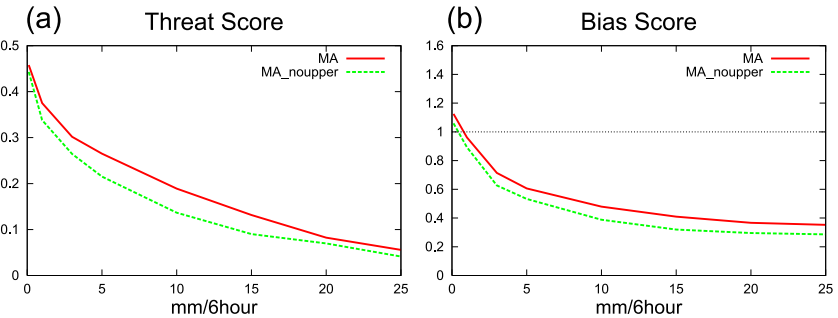

Fig. 2. (a) Threat scores of 6-hour accumulated rainfall averaged for 20 to 25 June 2008; (b) same as (a) but for bias scores. MA (MA_noupper) indicates the Meso 4D-Var (Meso 4D-Var without upper soundings) over China at 1200 UTC

the heat-conduction equation in NHM and Meso 4D-Var. The surface temperature of GA was substituted for the first-layer soil temperature on Meso 4D-Var, but temperatures at other layers were prepared using Japanese 25-year Reanalysis (JRA-25) data. The detailed procedure for considering the influence of the diurnal change is given in Section E-3-3 of Saito et al. (2010).

\section{Assimilation of precipitation data}

Although the satellite data are assimilated as retrieved water vapor and precipitation data in the Meso 4D-Var, they seemed to have little impact on predicting precipitation over China because the data are limited over the sea, located southeast of the model domain. Hence, in this study, 3-hour rainfall amounts observed by rain gauges in China and 1-hour rainfall analysis data from around the Beijing area (STEPS: Short-Term Ensemble Prediction System) were assimilated complementarily.

The STEPS data were obtained from the B08FDP component, in which the Australian Bureau of Meteorology (BOM) routinely produced data for their nowcasting system during the FDP experiment period. STEPS is a quantitative precipitation estimate (QPE) system at BOM that blends hourly rain-gauge rainfall with hourly radar rainfall (Bowler et al. 2006). In the B08FDP, some modifications were implemented, such as the alternation of the radar reflectivity factor $(\mathrm{Z})$ and the rainfall rate $(\mathrm{R})$ relation $(\mathrm{Z}-\mathrm{R}$ relation), and the adoption of radar quality-control algorithms (Seed 2009). Although the data covered only a domain of $500 \mathrm{~km}$ square around Beijing (Fig. 3b), the horizontal resolution of $2 \mathrm{~km}$ was sufficient to be assimilated in Meso 4D-Var.

These precipitation data were processed by averaging and interpolating them into the $20 \mathrm{~km}$ inner grids of Meso 4D-Var and were assimilated following Koizumi et al. (2005). Since we discarded any precipitation data of less than $0.5 \mathrm{~mm} \mathrm{hour}^{-1}$, norain information was not used in the assimilation process. This procedure was introduced because it was impossible to distinguish between a null report and no rain in the 3-hour accumulated raingauge data provided by CMA.

Figure $3 \mathrm{a}(3 \mathrm{~b})$ indicates the distribution of 3-hour accumulated rainfall observed by rain gauge (analyzed by STEPS). Figures 3c and $3 \mathrm{~d}$ present the corresponding rainfall in the analysis cycle of the Meso 4D-Var system. The rainfall around the Beijing area is weak in the experiment without precipitation-data assimilation (MA; Fig. 3c) compared with the rain-gauge observations (Fig. 3a). By contrast, the experiment with precipitation-data assimilation (MA_CRAIN) successfully captures the features of the distribution of observed rainfall around the Beijing area (Fig. 3d). This result demonstrates that these rainfall data were assimilated properly.

\section{Verification of forecasts}

In the experiment conducted during the 2008 summer season, we verified the performance of the control forecasts of the 

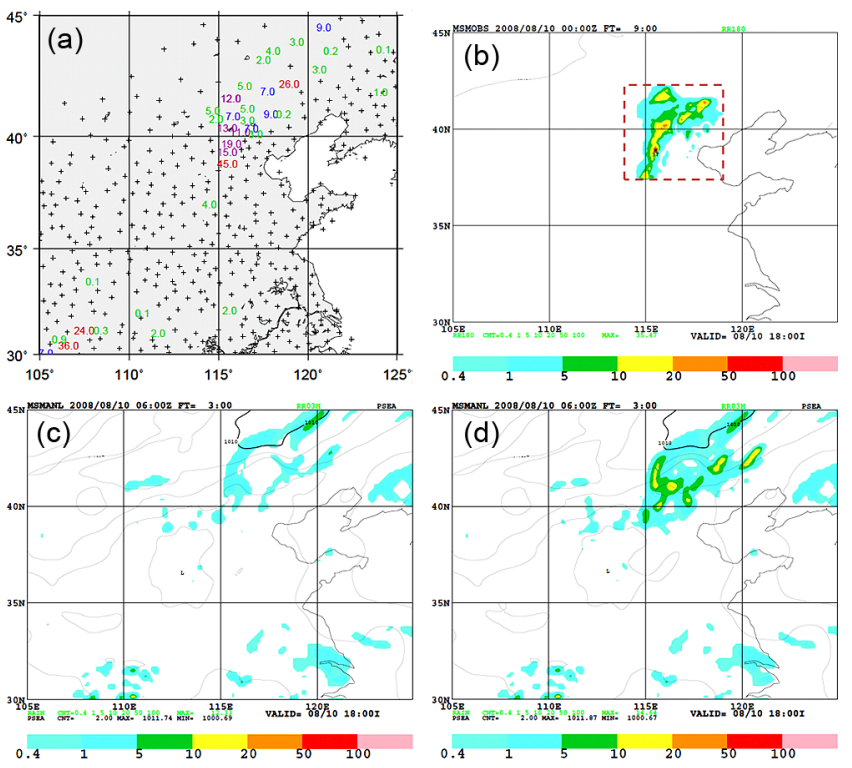

Fig. 3. 3-hour accumulated rainfall at 0900 UTC, 10 August 2008. (a) Rain-gauge observations ("+" indicates null data). (b) Analysis by STEPS (the square surrounded by dashed lines). (c) Meso 4D-Var analysis without precipitation-data assimilation. (d) Same as (c) but with precipitation-data assimilation.

MRI/JMA MEP system using threat and bias scores from 6-hour accumulated precipitation. In the final experiment of B08RDP, we adopted the Meso 4D-Var analysis with precipitation assimilation (MA_CRAIN) to prepare the initial conditions for the control run. For comparison, additional experiments were performed after the final experiment using Meso 4D-Var without assimilation of precipitation data in China (MA) and the JMA global analysis (GA). Although the MA experiment was not carried out in real time, the assimilated observations were the same as in the MA CRAIN experiment, especially the upper soundings at 1200 UTC. The GA experiment was performed for comparison, using MA and MA_CRAIN as a reference. GA is produced by the JMA global 4D-Var with a horizontal resolution of about $80 \mathrm{~km}$. The assimilation length is 6 hours, with observational data taken within 3 hours before and after analysis time being assimilated. For details, see JMA (2007).

Figure 4 compares threat scores, and Fig. 5 compares bias scores, both averaged from 25 July to 23 August 2008. For threat scores against the intensity of precipitation (Fig. 4a), we can see that the Meso 4D-Var results were superior to GA at almost all thresholds. With precipitation assimilation, the scores were further improved, particularly for weak and moderate rains (Figs. $4 \mathrm{~b}$ and $4 \mathrm{c})$. For the bias scores, precipitation assimilation also contributed to the improvement of the scores for weak and moderate rains (Fig. 5a), though the effect becomes unclear in the latter half of the forecast period. The most notable characteristic is that the bias scores of MA_CRAIN and MA at the beginning of the forecast period (Figs. $5 \bar{b}, 5 \mathrm{c}$, and $6 \mathrm{~d}$ ) are considerably better than those of GA. Implementing NHM in the outer model of the 4D-Var partly contributed to improving the model spin-up.

It is also important to examine the error statistics of other variables when evaluating the validity of the precipitation assimilation. Figure 6 presents the time series of the mean error (ME) and root mean square error (RMSE) for the surface temperature and relative humidity, averaged over the experiment period. For the surface temperature (Figs. 6a and 6b), we can see that the negative bias of MA_CRAIN was slightly larger at the beginning of the forecast period than that of MA, whereas the RMSEs were almost identical. This seems attributable to the fact that the assimilation of rainfall rates mostly enhanced the precipitation in analysis cycles, leading to a lowered surface temperature through
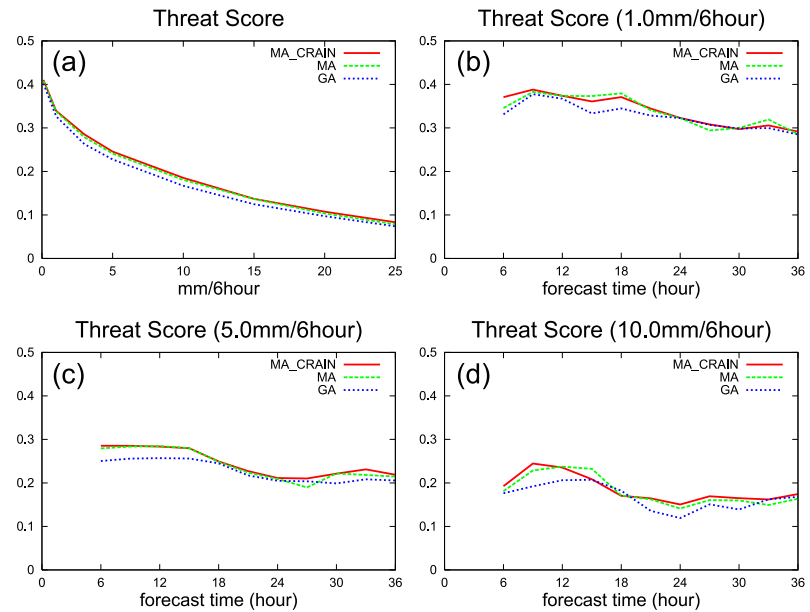

Fig. 4. (a) Threat scores for 6-hour accumulated precipitation against precipitation intensity for 30 days, from 25 July to 23 August 2008. MA_CRAIN (MA) indicates forecasts from the Meso 4D-Var with (without) precipitation assimilation. GA presents forecasts from the JMA global analysis. (b) Same as (a) but time evolution of threat scores at a threshold of $1 \mathrm{~mm}$. (c) Same as (b) but at a threshold of $5 \mathrm{~mm}$. (d) Same as (b) but at a threshold of $10 \mathrm{~mm}$.
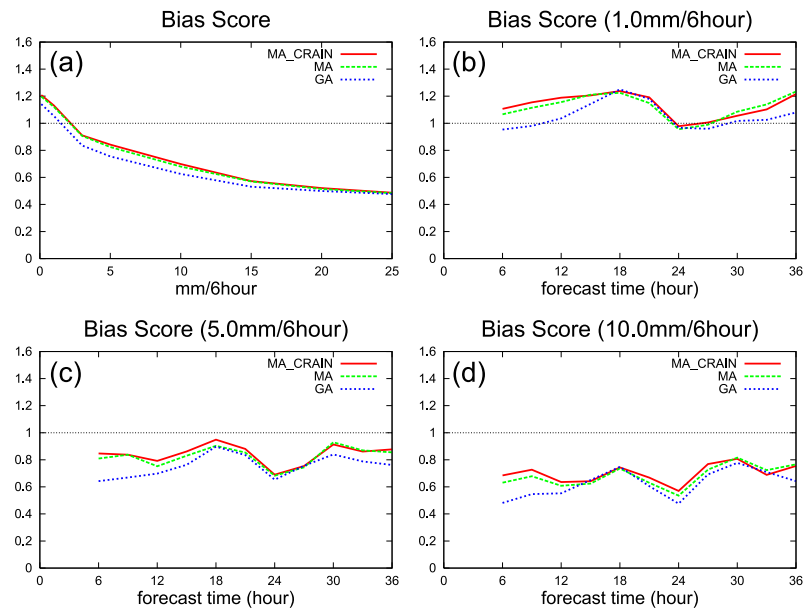

Fig. 5. Same as Fig. 4, but bias scores.
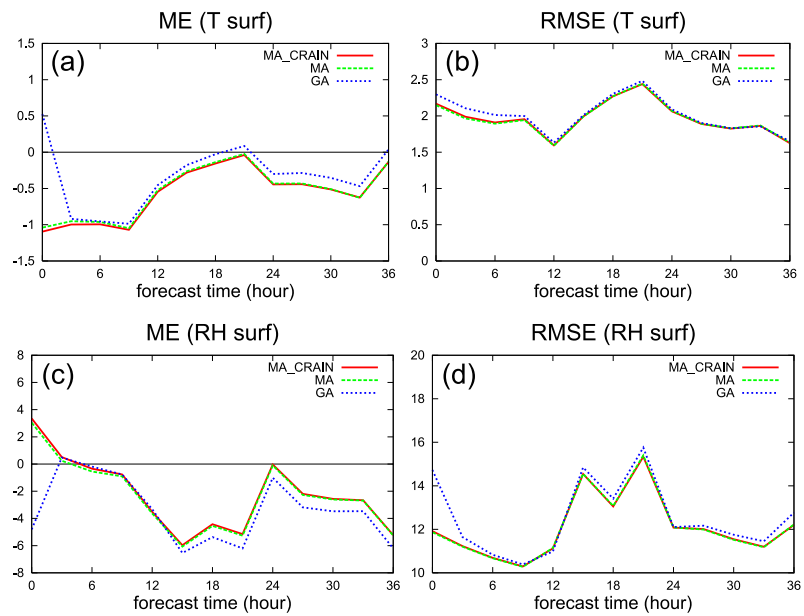

Fig. 6. (a) Mean error for surface temperature. (b) Same as (a) but rootmean-square error. (c) Same as (a) but for surface relative humidity. (d) Same as (c) but root-mean-square error. 
the evaporation of raindrops and advection of cold air. For the relative humidity at surface level (Figs. 6c and 6d), the bias of MA_CRAIN was again slightly increased, highlighting the lowered temperature. However, the RMSE was not degraded. These results suggest that the assimilation of rainfall amounts has a clear advantage in precipitation forecasts and is almost neutral regarding the prediction of surface temperature and relative humidity.

Figures 4 and 5 indicate that MA was superior to GA for the initial condition of the mesoscale model forecast, despite the advantage of having observational data taken after the analysis time assimilated in GA. This is partly because of dry bias at the surface level (Fig. 6c) caused by the difference in land processes between GA and MA mentioned above. This discrepancy yielded higher land-surface temperatures and lower relative humidity in GA than in MA, which would lead to deterioration of the precipitation forecast in the subsequent model. Although GA was used as a first guess at the beginning of the MA cycle, the 6-hour assimilation period was long enough to reduce the bias of surface temperature and relative humidity with observational data.

It should be noted that there remains a difficulty in predicting intense rainfall. We can see that the advantages of assimilating precipitation data were not so obvious for intense rainfall (Figs. $4 \mathrm{~d}$ and $5 \mathrm{~d}$ ). This might be partly related to the forecast model resolution of $15 \mathrm{~km}$ in the B08RDP experiment, where cumulus convection was parameterized using a modified Kain-Fritsch scheme. Another cause may be in the initial condition; Meso 4D-Var is a hydrostatic data assimilation method without cloud microphysics. The horizontal resolution of the inner model is 20 $\mathrm{km}$, and the precipitation intensities were assimilated in cube-root form in order to avoid excess influence of the data.

\section{Summary and conclusions}

In this study, we modified the JMA mesoscale 4D-Var analysis system so as to permit its use in the Beijing area and ran the assimilation system routinely during the B08RDP experiment period in 2008. For near-real-time operation, the influence of the cutoff time of observational data in China was investigated, and it was found that upper soundings over the China area at 1200 UTC are critical for the subsequent model forecast. This suggests that a longer cut-off time might be desirable to improve the analysis fields, even in the operational mesoscale analysis.

In order to produce accurate initial fields, particularly for precipitation forecasts, precipitation data over China were assimilated. In addition, the incremental forecast of the last window of the Meso 4D-Var was performed using NHM, the same model as that of the control forecast. These modifications considerably improved the verification scores for rainfall prediction at the beginning of the forecast. The results demonstrate that the assimilation of precipitation data is effective even for an area where successive rainfall observations are sparse.

Our results indicate that the Meso 4D-Var utilized in this study was superior to the JMA global analysis. This was the first case in which the Meso 4D-Var analysis system was applied to fullscale international numerical experimentation. The relocation of a regional data-assimilation system performed for this study will be useful for future studies requiring high-resolution analysis fields overseas.

\section{Acknowledgments}

We are grateful to two anonymous referees for their valuable comments, which significantly improved the manuscript. The authors also would like to thank Alan W. Seed of the Bureau of Meteorology, Australia, for providing the STEPS data. The help of Ko Koizumi, Yoshihiro Ishikawa, Tabito Hara, and Kohei Aranami of the Numerical Prediction Division of JMA is gratefully acknowledged. Thanks also to Gong Jaindong and the staff of NMC/CMA for their great effort in conducting the WWRP Beijing 2008 FDP/RDP project. This work was partly supported by the Grant-in-Aid for Scientific Research, "Study of advanced data assimilation and cloud resolving ensemble technique for prediction of local heavy rainfall". Numerical computations in this study were performed using a NEC SX-6 super-computer system at MRI.

\section{References}

Aranami, K., and T. Hara, 2006: The modifications of NHM. NPD Lecture Note on Numerical Weather Prediction in 2006, 5558, (in Japanese).

Bowler, N. E., C. E. Pierce, and A. W. Seed, 2006: STEPS: A probabilistic precipitation forecasting scheme which merges extrapolation nowcast with downscaled NWP. Quart. J. Roy. Meteor. Soc., 132, 2127-2155.

Ishida, J., and K. Saito, 2005: Initialization scheme for water substances in the operational NHM. CAS/JSC WGNE Research Activities in Atmospheric and Oceanic Modelling. 35, 1.171.18.

Ishikawa, Y., and K. Koizumi, 2002: Mesoscale 4-dimensional variational data assimilation. Annual report of Numerical Prediction Division, 48, 37-59, (in Japanese).

Japan Meteorological Agency, 2007: Outline of the Operational Numerical Weather Prediction at the Japan Meteorological Agency, 194 pp, (available online at http://www.jma.go.jp/ jma/jma-eng/jma-center/nwp/outline-nwp/index.htm, accessed 2009. 8. 1).

Koizumi, K., Y. Ishikawa, and T. Tsuyuki, 2005: Assimilation of precipitation data to the JMA mesoscale model with a fourdimensional variational method and its impact on precipitation forecasts. SOLA, 1, 45-48.

Parrish, D. F., and J. C. Derber, 1992: The national meteorological center's spectral statistical-interpolation analysis system. Mon. Wea. Rev., 120, 1747-1763.

Saito, K., T. Fujita, Y. Yamada, J. Ishida, Y. Kumagai, K. Aranami, S. Ohmori, R. Nagasawa, S. Kumagai, C. Muroi, T. Kato, H. Eito, and Y. Yamazaki, 2006: The operational JMA nonhydrostatic mesoscale model. Mon. Wea. Rev., 134, 12661298.

Saito, K., M. Kunii, M. Hara, H. Seko, T. Hara, M. Yamaguchi, T. Miyoshi, and W. Wong, 2010: WWRP Beijing Olympics 2008 Forecast Demonstration/Research and Development Project (B08FDP/RDP). Tech. Rep. MRI, 62, 210 pp, (in press).

Seed, A. W., 2009: STEPS in B08FDP. Forth WWRP-B08FDP/ RDP Workshop. 21-23 April 2009, Guang Zhou, China.

Manuscript received 16 December 2009, accepted 16 February 2010 SOLA: http://www.jstage.jst.go.jp/browse/sola/ 